\title{
Suicide in cancer patients in South East England from 1996 to 2005: a population-based study
}

\author{
D Robinson*,', C Renshaw', C Okello', H Møller' and EA Davies' \\ 'Division of Cancer Studies, King's College London, Thames Cancer Registry, I st Floor Capital House, 42 Weston Street, London SEI 3QD, UK
}

BACKGROUND: Studies from around the world have shown that suicide risk is increased in cancer patients, but no previous detailed analysis has been carried out in England.

METHODS: We calculated standardised mortality ratios (SMRs) for suicide in 206 I 29 men and 2I I 443 women diagnosed with cancer in South East England between 1996 and 2005, relative to suicide rates in the general population.

RESULTS: We found a significantly increased risk of suicide in men (SMR I.45, 95\% confidence interval (Cl) $1.20-1.73)$ and a moderately increased risk in women (SMR I.19,95\% Cl 0.88-1.57). In both sexes, relative risk of suicide was greatest in the first year after cancer diagnosis (SMR for men 2.42, 95\% Cl I.84-3.13; SMR for women 1.44, 95\% Cl 0.82-2.33), and was also greater in individuals diagnosed with types of cancer with high fatality (SMR for men 2.67, 95\% Cl I.7I -3.97; SMR for women 2.17, 95\% Cl $0.80-4.73)$.

CONCLUSION: There is a critical period immediately after the diagnosis of cancer during which the excess risk of suicide is particularly high. Carers need to be aware of the importance of attending to both the physical and emotional needs of cancer patients and cancer survivors.

British Journal of Cancer (2009) I 0 I, 198-201. doi:10.1038/sj.bjc.6605 II0 www.bjcancer.com

Published online 26 May 2009

(C) 2009 Cancer Research UK

Keywords: suicide; standardised mortality ratio; fatality; deprivation

Patients diagnosed with life-threatening conditions such as cancer experience painful emotional reactions, which can lead to suicidal thoughts. The risk of suicide in cancer patients has been reported as elevated relative to that of the general population in several countries: Italy (Crocetti et al, 1998; Miccinesi et al, 2004), Switzerland (Chatton-Reith et al, 1990; Levi et al, 1991), Denmark (Storm et al, 1992; Yousaf et al, 2005; Christensen et al, 2006; Schairer et al, 2006), Norway (Hem et al, 2004; Schairer et al, 2006), Sweden (Allebeck et al, 1989; Allebeck and Bolund, 1991; Björkenstam et al, 2005; Schairer et al, 2006; Björkholm et al, 2007), Finland (Louhivuori and Hakama, 1979; Schairer et al, 2006), Estonia (Innos et al, 2003), Australia (Dormer et al, 2008), Japan (Tanaka et al, 1999), Scotland (Camidge et al, 2007) and the United States of America (Fox et al, 1982; Llorente et al, 2005; Kendal, 2007; Miller et al, 2008; Misono et al, 2008). The majority of studies report a higher relative risk in men than in women. The risk has been shown to be greatest in the first months after diagnosis (Crocetti et al, 1998; Tanaka et al, 1999; Innos et al, 2003; Hem et al, 2004; Llorente et al, 2005; Yousaf et al, 2005; Dormer et al, 2008), and to increase with the severity of the disease (Louhivuori and Hakama, 1979; Storm et al, 1992; Tanaka et al, 1999; Miccinesi et al, 2004; Björkenstam et al, 2005; Yousaf et al, 2005; Kendal, 2007; Dormer et al, 2008).

A series of recent initiatives in cancer care in England have sought to improve the provision and quality of supportive and palliative care services (National Institute for Clinical Excellence, 2004), and to improve the quality of life of cancer survivors

*Correspondence: Dr D Robinson; E-mail: dave.robinson@kcl.ac.uk Revised 24 April 2009; accepted I May 2009; published online 26 May 2009
(Department of Health, 2007). In the year following the diagnosis of cancer, around 1 in 10 patients are reported to experience symptoms of either depression or anxiety severe enough to require intervention by specialist psychological or psychiatric services (National Institute for Clinical Excellence, 2004). To our knowledge no previous detailed analysis of suicide risk in individuals with cancer has been carried out in England, although a recent study, covering the period 1981 to 1995 , has reported on hospital admissions and deaths relating to deliberate self-harm in cancer patients in Scotland (Camidge et al, 2007). In this study, we aim to provide new information relating to suicide risk in patients diagnosed with cancer in South East England during the more recent time period of 1996 to 2005.

\section{METHODS}

The records of all patients diagnosed with an invasive cancer between 1996 and 2005 were extracted from the database of the Thames Cancer Registry. This is a population-based registry, covering around 12 million people residing in an area of South East England comprising London, Kent, Surrey and Sussex. We excluded patients registered only from a death certificate or for whom the recorded date of diagnosis was the same as the date of death (9.5\% of all cases), and those with a date of death but no recorded cause of death $(0.54 \%$ of all deaths $)$. We also excluded patients aged less than 15 years at cancer diagnosis, as suicide rates in the general population are not available for this age group. Cases of suicide were identified either from the ICD cause of death code (where present) or from appropriate text fields in the death certificate. The relevant ICD-9 codes were E950-E959 and 
E980-E989 (excluding E988.8), with corresponding ICD-10 codes X60-X84 and Y10-Y34 (but excluding Y33.9 where a coroner's verdict was pending). These were chosen to be consistent with those used by National Statistics (Brock et al, 2006). Keywords searched for in the text fields were 'suicide', 'killed him/herself, 'own life' and 'overdose'. Of the 166 suicides identified, 8 (4.8\%) were found by text analysis alone.

Standardised mortality ratios (SMRs) were calculated by dividing the observed numbers of suicides by the numbers expected, derived from age/sex/calendar period-specific suicide rates for the London and South East Coast Strategic Health Authorities provided by the Office for National Statistics. Time at risk was calculated from cancer diagnosis to death or end of the study period (31 December 2005). For individuals with more than one cancer diagnosis, the date of the first cancer was taken as the start of the at-risk period. SMRs were calculated separately for men and women, and were examined in relation to a number of factors: time since cancer diagnosis, age at diagnosis, stage of disease ( 1 = localised; $2=$ extension beyond the organ of origin; $3=$ local lymph node involvement; $4=$ metastases), fatality of the cancer type (based on relative survival figures, with those cancer types with a 5 -year survival of less than $10 \%$ being classified as having 'high' fatality), calendar period of diagnosis and deprivation (measured in quintiles using the income domain of the Indices of Multiple Deprivation (IMD) 2004, assigned on the basis of place of residence at the time of diagnosis (Neighbourhood Renewal Unit, 2004)). A Cox proportional hazards regression model was fitted using all of these factors as covariates, in an attempt to estimate their independent and joint effects on the risk of committing suicide after being diagnosed with cancer.

\section{RESULTS}

A total of 206129 male and 211443 female cancer patients with a combined follow-up of 1.1 million person-years were included in the analysis. Among these, we observed 166 suicides (117 in men and 49 in women). The mean age at diagnosis of first cancer in those committing suicide was 67.9 years in men and 63.4 years in women. Mean age at suicide was 69.9 years in men and 65.9 years in women. Table 1 shows the SMRs and $95 \%$ confidence intervals (CIs) for suicide by sex and time since diagnosis. Overall, there was a significantly increased risk of suicide in men (SMR 1.45; 95\% CI $1.20-1.73)$. In women, the SMR was lower and did not reach statistical significance (SMR 1.19, 95\% CI $0.88-1.57$ ). In both sexes there was a downward trend in relative risk of suicide with increasing time since diagnosis: SMRs at $<1,1-5$ and $>5$ years after diagnosis were $2.42(1.84-3.13), 1.04(0.76-1.39)$ and 1.01 $(0.54-1.73)$ for men and $1.44(0.82-2.33), 1.10(0.71-1.63)$ and $1.08(0.47-2.14)$ for women.

Table 2 shows the mutually adjusted hazard ratios from the Cox regression analysis. In both men and women, the risk of suicide was highest in the first year after cancer diagnosis. Overall, there was a suggestion of increasing risk of suicide with increasing age. The more fatal types of cancer carried the highest risk of suicide in both men and women, but a strong effect of advanced stage of disease was evident only in women. There were no significant trends in suicide risk over the period studied. There was a tendency for those from more deprived areas (higher IMD 2004 quintiles) to be at greater risk than those from more affluent areas: suicide risk was highest in the socio-economically deprived groups of women.

\section{DISCUSSION}

We have found an excess of suicides in patients diagnosed with cancer in South East England, which is most pronounced in the first year following diagnosis and higher in men than in women. These results are generally consistent with previous findings. In
Table I Standardised mortality ratios for suicide in cancer patients, by sex and time since diagnosis

\begin{tabular}{|c|c|c|c|c|}
\hline & \multicolumn{3}{|c|}{ Years since diagnosis } & \multirow[b]{2}{*}{ Total } \\
\hline & $<\mathbf{I}$ & I-5 & $>5$ & \\
\hline $\begin{array}{l}\text { Suicides } \\
\text { Males }\end{array}$ & 58 & 46 & 13 & 117 \\
\hline SMR & 2.42 & 1.04 & 1.01 & 1.45 \\
\hline $95 \% \mathrm{Cl}$ & $1.84-3.13$ & $0.76-1.39$ & $0.54-1.73$ & $1.20-1.73$ \\
\hline $\begin{array}{l}\text { Suicides } \\
\text { Females }\end{array}$ & 16 & 25 & 8 & 49 \\
\hline SMR & 1.44 & 1.10 & 1.08 & 1.19 \\
\hline $95 \% \mathrm{Cl}$ & $0.82-2.33$ & $0.71-1.63$ & $0.47-2.14$ & $0.88-1.57$ \\
\hline $\begin{array}{l}\text { Suicides } \\
\text { All }\end{array}$ & 74 & 71 & 21 & 166 \\
\hline SMR & 2.11 & 1.06 & 1.04 & 1.36 \\
\hline $95 \% \mathrm{Cl}$ & $1.65-2.65$ & $0.83-1.34$ & $0.64-1.59$ & $1.16-1.58$ \\
\hline
\end{tabular}

$\mathrm{SMR}=$ standardised mortality ratio; $\mathrm{Cl}=$ confidence interval.

Table 2 Adjusted hazard ratios and 95\% confidence intervals for suicide in cancer patients in South East England 1996-2005

\begin{tabular}{|c|c|c|c|}
\hline Factor & Males & Females & All \\
\hline \multicolumn{4}{|c|}{ Time since diagnosis (years) } \\
\hline $0-1$ & $2.09(1.39-3.15)$ & $1.14(0.59-2.22)$ & $1.78(1.26-2.50)$ \\
\hline$>1$ & 1.00 & 1.00 & 1.00 \\
\hline \multicolumn{4}{|c|}{ Age at diagnosis (years) } \\
\hline $15-60$ & 1.00 & 1.00 & 1.00 \\
\hline $61-75$ & $0.78(0.24-2.59)$ & $2.88(0.46-18.04)$ & $1.29(0.47-3.54)$ \\
\hline$>75$ & $1.24(0.24-6.44)$ & $1.37(0.10-18.66)$ & $1.57(0.40-6.17)$ \\
\hline \multicolumn{4}{|l|}{ Stage } \\
\hline $1-2$ & 1.00 & 1.00 & 1.00 \\
\hline $3-4$ & $0.79(0.43-1.44)$ & $2.41(1.25-4.64)$ & $1.16(0.76-1.76)$ \\
\hline$N / K$ & $1.38(0.94-2.05)$ & $1.10(0.53-2.29)$ & $1.3 \mid(0.93-1.85)$ \\
\hline \multicolumn{4}{|c|}{ Fatality of cancer } \\
\hline Low & 1.00 & 1.00 & 1.00 \\
\hline High & $1.76(1.10-2.81)$ & $1.57(0.65-3.81)$ & $1.87(1.24-2.82)$ \\
\hline \multicolumn{4}{|c|}{ Period of diagnosis } \\
\hline $1996-1999$ & 1.00 & 1.00 & 1.00 \\
\hline $2000-2002$ & $0.98(0.64-1.49)$ & $0.96(0.50-1.83)$ & $1.00(0.70-1.42)$ \\
\hline $2003-2005$ & $1.10(0.66-1.85)$ & $1.07(0.44-2.57)$ & $1.12(0.72-1.75)$ \\
\hline \multicolumn{4}{|c|}{ IMD 2004 quintile } \\
\hline $1-2$ & 1.00 & 1.00 & 1.00 \\
\hline 3 & $1.07(0.65-1.75)$ & $1.76(0.84-3.70)$ & $1.24(0.82-1.87)$ \\
\hline $4-5$ & $1.06(0.7 \mid-1.60)$ & $1.45(0.75-2.82)$ & $1.17(0.83-1.65)$ \\
\hline
\end{tabular}

the majority of studies that have compared suicide risks between the sexes, men were found to have a higher relative risk than women (Fox et al, 1982; Allebeck et al, 1989; Levi et al, 1991; Innos et al, 2003; Hem et al, 2004; Miccinesi et al, 2004; Yousaf et al, 2005; Dormer et al, 2008; Misono et al, 2008).

In both men and women we found the relative risk of suicide to be greatest in the first year after diagnosis. This is also consistent with many of the previous studies, which found a maximum risk within the first few months (Crocetti et al, 1998; Tanaka et al, 1999; Innos et al, 2003; Hem et al, 2004; Llorente et al, 2005; Yousaf et al, 2005; Dormer et al, 2008) or the first 1-2 years (Allebeck et al, 1989; Chatton-Reith et al, 1990; Levi et al, 1991; Storm et al, 1992; Miccinesi et al, 2004; Björkholm et al, 2007). Dormer et al (2008) 
found a peak risk in the first 3 months, with a second period of increased risk 12-14 months after diagnosis, which they suggested might be a response to cancer recurrence or treatment failure. An international study of women with breast cancer (Schairer et al, 2006) found an elevated risk throughout the follow-up period, including more than 25 years after diagnosis.

Some investigators (Chatton-Reith et al, 1990; Miccinesi et al, 2004; Schairer et al, 2006) have found an increase in relative risk with increasing age. Others (Fox et al, 1982; Allebeck et al, 1989; Levi et al, 1991; Björkenstam et al, 2005; Yousaf et al, 2005; Dormer et al, 2008) found no such relationship, whereas Innos et al (2003) found the highest risk in men aged 15-49, with a tendency for the risk to decline in older age groups. In our study, there was a suggestion of increasing suicide risk with increasing age.

Suicide risk has been shown to be associated with stage of disease, with higher risks in patients with non-localised disease (Louhivuori and Hakama, 1979; Storm et al, 1992; Yousaf et al, 2005) or distant metastases (Tanaka et al, 1999; Kendal, 2007). In a case-control study of Americans aged 65 or more (Miller et al, 2008), the only medical condition found to be associated with suicide was cancer, and metastases were significantly more common in cancer patients who committed suicide than in those who did not. In our study, the risk of suicide was significantly higher in women with later stage disease, but not in men. We found a significantly raised SMR in men with unknown stage $(1.78$, $95 \%$ CI 1.31-2.37). However, this group of patients were on average older and had shorter survival than the staged patients, and the relationship became non-significant after adjusting for these factors in the full model.

Suicide risk has also been shown to be higher in patients diagnosed with cancers that have a poor prognosis (Storm et al, 1992; Yousaf et al, 2005; Dormer et al, 2008) or a low survival rate (Miccinesi et al, 2004; Björkenstam et al, 2005). Misono et al (2008) found the risk to be highest for lung, stomach or head and neck cancers, whereas Innos et al (2003) found the greatest risks in men with cancers of the oesophagus or pancreas. We found significantly higher risks associated with cancers at sites with high fatality rates (5-year relative survival of less than $10 \%$ ) when compared with those at other sites, with SMRs of $2.42(1.84-3.13)$ for men and $1.44(0.82-2.33)$ for women.

There is some evidence from other studies (Hem et al, 2004; Miccinesi et al, 2004; Björkenstam et al, 2005) that the relative risk of suicide in cancer patients is decreasing in more recent years. This may be due to new treatments, increased survival and a better public awareness that cancer is not necessarily a fatal condition all of which should improve a patient's reaction to a diagnosis of cancer. However, Fox et al (1982) found no significant trend with decade of diagnosis, and two Danish studies (Storm et al, 1992; Yousaf et al, 2005) found increasing risks over time. After adjusting for confounding factors, we found no significant trend over time in the population of South East England.

Chatton-Reith et al (1990) found suicide relative risk to be lower in the upper socio-economic classes. There is a suggestion of this in our data, with lower risks in the two most affluent quintiles, although the differences did not reach statistical significance and were attenuated after adjustment for other factors, including disease stage.

The results of our and other studies indicate that there is a critical period immediately after diagnosis during which the excess risk of suicide in cancer patients is particularly high. Patients who survive this initial period are much less likely to commit suicide, although the risk can remain elevated for many years. The risk of suicide is especially high in those diagnosed with cancers such as lung, pancreas or oesophagus, where the prognosis is poor and the symptoms painful or likely to interfere with vital functions such as breathing and eating. The SMRs for these cancers in the first year after diagnosis were $4.60(2.51-7.72), 6.79(1.40-19.83)$ and 6.52 $(2.12-15.22)$ respectively.

Studies (Henriksson et al, 1995; Akechi et al, 2001, 2002a, b; Filiberti et al, 2001; Smith et al, 2004; Walker et al, 2008) have consistently shown that substantial pain, major depression, loss of autonomy and independence, emotional distress and impaired physical functioning are the clinical factors most commonly associated with suicidal thoughts in cancer patients. One recent survey of nearly 3000 cancer patients attending a regional cancer centre in Scotland found that almost $8 \%$ reported having thoughts of being better off dead or of hurting themselves in some way for at least several days in the previous 2 weeks (Walker et al, 2008). As pointed out, not all of these patients will attempt to harm themselves, but acknowledgment of emotional distress should be a core aspect of modern cancer care, together with careful control of symptoms such as pain. As stressed by Maliski et al (2003), awareness is important in attending to both the physical and emotional needs of cancer patients and cancer survivors.

\section{REFERENCES}

Akechi T, Nakano T, Akizuki N, Nakanishi T, Yoshikawa E, Okamura H, Uchitomi Y (2002a) Clinical factors associated with suicidality in cancer patients. Jpn J Clin Oncol 32: 506-511

Akechi T, Okamura H, Nishiwaki Y, Uchitomi Y (2002b) Predictive factors for suicidal ideation in patients with unresectable lung carcinoma A 6-month follow-up study. Cancer 95: 1085-1093

Akechi T, Okamura H, Yamawaki S, Uchitomi Y (2001) Why do some cancer patients with depression desire an early death and others do not? Psychosomatics 42: $141-145$

Allebeck P, Bolund C (1991) Suicides and suicide attempts in cancer patients. Psychol Med 21: 979-984

Allebeck P, Bolund C, Ringbäck G (1989) Increased suicide rate in cancer patients. A cohort study based on the Swedish cancer-environment register. J Clin Epidemiol 42: 611-616

Björkenstam C, Edberg A, Ayoubi S, Rosén M (2005) Are cancer patients at higher suicide risk than the general population? A nationwide register study in Sweden from 1965 to 1999. Scand J Public Health 33: $208-214$

Björkholm M, Hultcrantz M, Kristinsson S, Brandt L, Ekbom A, Derolf A (2007) Suicide in multiple myeloma and acute myeloid leukaemia. Ann Oncol 18: $1122-1123$

Brock A, Baker A, Griffiths C, Jackson G, Fegan G, Marshall D (2006) Suicide trends and geographical variations in the United Kingdom, 1991-2004. Health Stat Q 31: 6-22

Camidge DR, Stockton DL, Frame S, Wood R, Bain M, Bateman DN (2007) Hospital admissions and deaths relating to deliberate self-harm and accidents within 5 years of a cancer diagnosis: a national study in Scotland, UK. Br J Cancer 96: $752-757$

Chatton-Reith J, el May H, Raymond L (1990) The risk of suicide in cancer patients derived from a cancer registry. Rev Epidémiol Santé Publique 38: $125-131$

Christensen M-L M, Yousaf U, Engholm G, Storm HH (2006) Increased suicide risk among Danish women with non-melanoma skin cancer, 1971 - 1999. Eur J Cancer Prev 15: 266-268

Crocetti E, Arniani S, Acciai S, Barchielli A, Buiatti E (1998) High suicide mortality soon after diagnosis among cancer patients in central Italy. Br J Cancer 77: 1194-1196

Department of Health (2007) Cancer Reform Strategy. London: DoH

Dormer NRC, McCaul KA, Kristjanson LJ (2008) Risk of suicide in cancer patients in Western Australia, 1981-2002. Med J Aust 188: 140-143

Filiberti A, Ripamonti C, Totis A, Ventfridda V, De Conno F, Contiero P, Tamburini M (2001) Characteristics of terminal cancer patients who commit suicide during a home palliative care program. J Pain Symptom Manage 22: $544-553$

Fox BH, Stanek III EJ, Boyd SC, Flannery JT (1982) Suicide rates among cancer patients in Connecticut. J Chronic Dis 35: 89-100

Hem E, Loge JH, Haldorsen T, Ekeberg $\varnothing$ (2004) Suicide risk in cancer patients from 1960 to 1999. J Clin Oncol 22: 4209-4216 
Henriksson MH, Isometsä ET, Hietanen PS, Aro HM, Lönnqvist JK (1995) Mental disorders in cancer suicides. J Affect Disord 36: 11-20

Innos K, Rahu K, Rahu M, Baburin A (2003) Suicides among cancer patients in Estonia: a population-based study. Eur J Cancer 39: $2223-2228$

Kendal WS (2007) Suicide and cancer: a gender-comparative study. Ann Oncol 18: $381-387$

Levi F, Bulliard JL, La Vecchia C (1991) Suicide risk among incident cases of cancer in the Swiss canton of Vaud. Oncology 48: 44-47

Llorente MD, Burke M, Gregory GR, Bosworth HB, Grambow SC, Horner RD, Golden A, Olsen EJ (2005) Prostate cancer: a significant risk factor for late-life suicide. Am J Geriatr Psychiatry 13: 195-201

Louhivuori KA, Hakama M (1979) Risk of suicide among cancer patients. Am J Epidemiol 109: 59-65

Maliski SL, Sarna L, Evangelista L, Padilla G (2003) The aftermath of lung cancer: balancing the good and the bad. Cancer Nurs 26: 237-244

Miccinesi G, Crocetti E, Benvenuti A, Paci E (2004) Suicide mortality is decreasing among cancer patients in Central Italy. Eur J Cancer 40: $1053-1057$

Miller M, Mogun H, Azrael D, Hempstead K, Solomon DH (2008) Cancer and the risk of suicide in older Americans. J Clin Oncol 26: $4720-4724$

Misono S, Weiss NS, Fann JR, Redman M, Yueh B (2008) Incidence of suicide in persons with cancer. J Clin Oncol 26: 4731-4738
National Institute for Clinical Excellence (2004) Guidance on Cancer Services: Improving Supportive and Palliative Care for Adults with Cancer. London: NICE

Neighbourhood Renewal Unit (2004) The English Indices of Deprivation 2004: Summary (revised). London: Office of the Deputy Prime Minister

Schairer C, Brown LM, Chen BE, Howard R, Lynch CF, Hall P, Storm H, Pukkala E, Anderson A, Kaijser M, Andersson M, Joensuu H, Fosså SD, Ganz PA, Travis LB (2006) Suicide after breast cancer: an international population-based study of 723810 women. J Natl Cancer Inst 98: $1416-1419$

Smith MT, Edwards RR, Robinson RC, Dworkin RH (2004) Suicidal ideation, plans, and attempts in chronic pain patients: factors associated with increased risk. Pain 111: 201-208

Storm HH, Christensen N, Jensen OM (1992) Suicides among Danish patients with cancer: 1971 to 1986. Cancer 69: 1507-1512

Tanaka H, Tsukuma H, Masaoka T, Ajiki W, Koyama Y, Kinoshita N, Hasuo S, Oshima A (1999) Suicide risk among cancer patients: experience at one medical center in Japan, 1978-1994. Jpn J Cancer Res 90: $812-817$

Walker J, Waters RA, Murray G, Swanson H, Hibberd CJ, Rush RW, Storey DJ, Strong VA, Fallon MT, Wall LR, Sharpe M (2008) Better off dead: suicidal thoughts in cancer patients. J Clin Oncol 26: 4725-4730

Yousaf U, Christensen M-LM, Engholm G, Storm HH (2005) Suicides among Danish cancer patients 1971-1999. Br J Cancer 92: 995 - 1000 